Article

\title{
GLUT10-Lacking in Arterial Tortuosity Syndrome-Is Localized to the Endoplasmic Reticulum of Human Fibroblasts
}

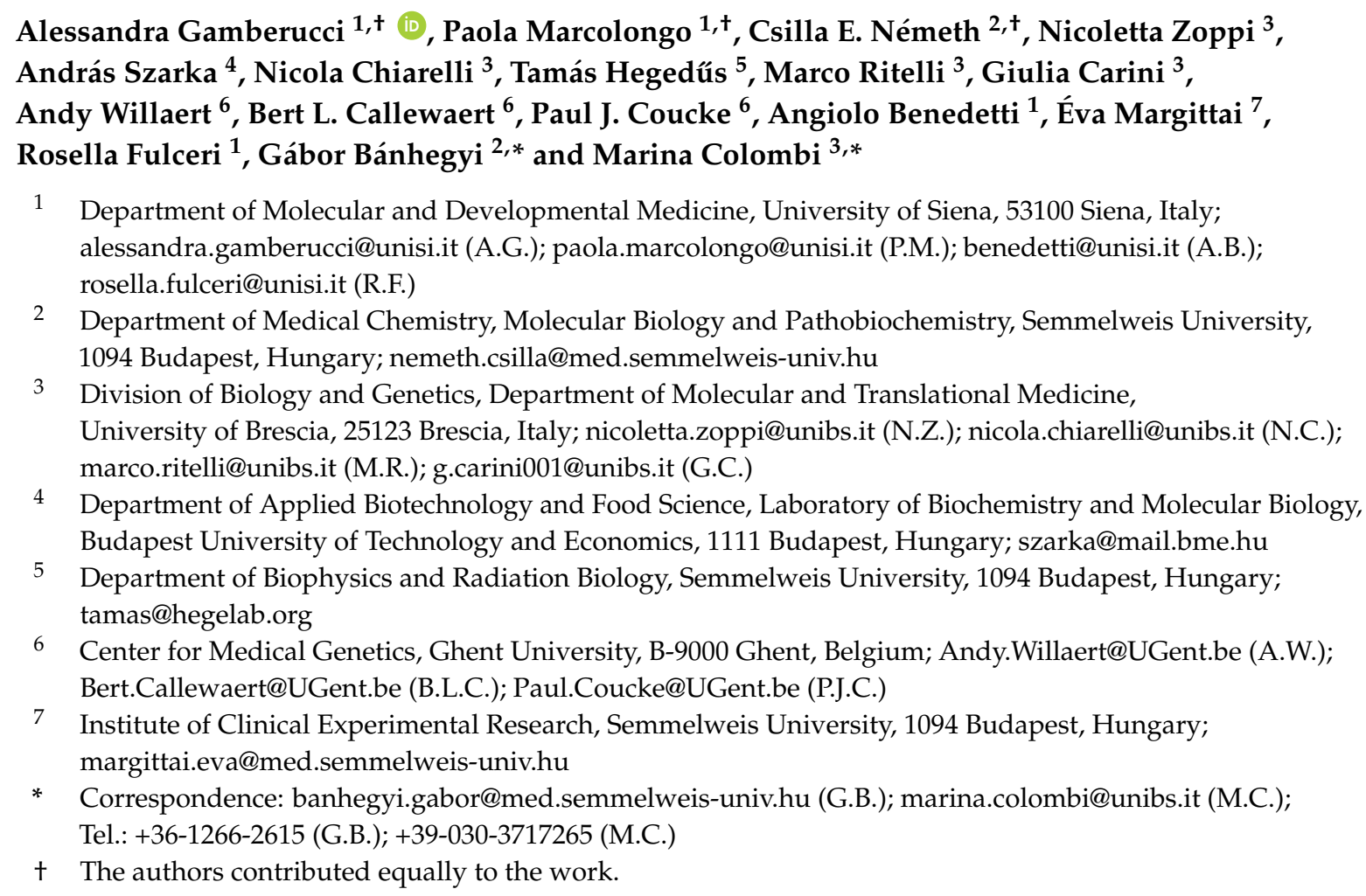

Received: 28 July 2017; Accepted: 13 August 2017; Published: 22 August 2017

\begin{abstract}
GLUT10 belongs to a family of transporters that catalyze the uptake of sugars/polyols by facilitated diffusion. Loss-of-function mutations in the SLC2A10 gene encoding GLUT10 are responsible for arterial tortuosity syndrome (ATS). Since subcellular distribution of the transporter is dubious, we aimed to clarify the localization of GLUT10. In silico GLUT10 localization prediction suggested its presence in the endoplasmic reticulum (ER). Immunoblotting showed the presence of GLUT10 protein in the microsomal, but not in mitochondrial fractions of human fibroblasts and liver tissue. An even cytosolic distribution with an intense perinuclear decoration of GLUT10 was demonstrated by immunofluorescence in human fibroblasts, whilst mitochondrial markers revealed a fully different decoration pattern. GLUT10 decoration was fully absent in fibroblasts from three ATS patients. Expression of exogenous, tagged GLUT10 in fibroblasts from an ATS patient revealed a strict co-localization with the ER marker protein disulfide isomerase (PDI). The results demonstrate that GLUT10 is present in the ER.
\end{abstract}

Keywords: GLUT10; arterial tortuosity syndrome; dehydroascorbic acid; endoplasmic reticulum; nuclear envelope; $\mathrm{Fe}^{2+}$ / 2-oxoglutarate dependent dehydrogenases 


\section{Introduction}

SLC2A (solute carrier 2A) gene family encodes glucose transporter (GLUT) proteins; presently 14 proteins grouped into three classes upon their sequence similarities. GLUT transporters are overwhelmingly uniporters, with the exception of GLUT13, which has been described as a myo-inositol- $\mathrm{H}^{+}$symporter. GLUT10, together with GLUT6, 8, 12 and 13, belongs to class 3 , which is the least investigated group of GLUT transporters. Their substrates, subcellular distribution and physiological functions have been hardly characterized [1].

The mRNA of GLUT10 has been documented in human brain, heart, lung, liver, skeletal muscle, pancreas, placenta and kidney [2], as well as in mouse brain [3]. GLUT10 is abundantly expressed in human aortic vascular smooth muscle cells [4], which strengthen its role in the pathophysiology of ATS (arterial tortuosity syndrome). GLUT10 expressed in Xenopus oocytes exhibited 2-deoxy-D-glucose transport activity, which was inhibited by D-glucose and D-galactose [2]. Recently, GLUT10-mediated dehydroascorbic acid transport was also identified [5]. The intracellular presence of the protein was firstly reported by Coucke and co-workers [6].

GLUT10 protein is encoded by the SLC2A10 gene [1]. Loss-of-function mutations of the SLC2A10 gene are responsible for arterial tortuosity syndrome (ATS, Online Mendelian Inheritance in Man compendium-OMIM-\#208050), which is a monogenic autosomal recessive heritable connective tissue disorder. The clinical phenotype of ATS includes the elongation, tortuosity and aneurysms of large arteries and stenosis of the pulmonary artery. To date, various $S L C 2 A 10$ gene mutations resulting in ATS have being identified [6-11]. However, the precise subcellular localization of GLUT10, and the missing physiological role of the transporter that results in the appearance of the ATS phenotype still remain debated. Three hypotheses have been proposed to connect the absence of GLUT10 activity and the connective tissue defects of ATS, as described in details in a previous paper from our laboratories [5]. Briefly, it was originally proposed that GLUT10 is a glucose transporter in the nuclear envelope (NE). Glucose-dependent upregulation of decorin, a transforming growth factor beta (TGF $\beta$ ) signaling inhibitor, would be absent in ATS, which also explains the activation of TGF $\beta$ pathway observed in ATS fibroblasts [6]. The second hypothesis supposes that GLUT10 mediates the transport of dehydroascorbic acid (DAA, the oxidized form of the antioxidant ascorbic acid, AA) across the mitochondrial inner membrane [12]. DAA can be reduced to AA in the mitochondrial matrix, which can neutralize reactive oxygen species (ROS) and protects the cell from oxidative effects. A third hypothesis postulates that GLUT10 behaves like a DAA transporter in the endoplasmic reticulum (ER) membranes [13,14]. DAA, upon being transported into the ER lumen, is reduced to AA and serves as a cofactor for $\mathrm{Fe}^{2+} / 2$-oxoglutarate dependent dioxygenases. These enzymes catalyze the hydroxylation of prolyl and lysyl residues by reactions crucial for maturation and folding of several extracellular matrix proteins. Moreover, GLUT10 in the ER-derived NE might favor the entry of DAA in the nucleus working as a cofactor (after reduction to AA) for nuclear $\mathrm{Fe}^{2+} / 2$-oxoglutarate-dependent dioxygenases involved in epigenetic modifications of histones and nucleic acids as hypothesized in [15].

In a recent paper, we observed that DAA uptake is present in the intracellular compartments of human normal fibroblasts, but dramatically diminished in fibroblasts from ATS patients [5]. Moreover, we demonstrated that in vitro-translated GLUT10 protein mediates DAA transport in proteoliposomes [5]. These observations suggest that GLUT10 can transport DAA and indicate its localization in cellular endomembranes.

Since there is no consensus with respect to the subcellular distribution of GLUT10, the aim of the present study was to unambiguously clarify the localization of this transporter. Obviously, the intracellular position of GLUT10 is crucial for further definition of its function and the clarification of ATS pathogenesis. 


\section{Results}

\subsection{In Silico Prediction of Subcellular Localization of GLUT10}

An anticipatory in silico search for the prediction of the subcellular distribution of GLUT10 indicated a relatively high probability of ER localization and an absolutely low probability of mitochondrial occurrence for GLUT10 (Table 1). Moreover the coding sequence for human GLUT10 possesses the ER retention signal YXXI/V motifs in C-terminus [16] and a Lys-Arg-Arg (KRR) motif in C-terminus that is also an ER retention signal [17].

Table 1. Subcellular localization of GLUT10 predicted by in silico analysis.

\begin{tabular}{|c|c|c|c|c|c|c|c|c|}
\hline Location & Target $P$ & Mitoprot & Predotar & PSORT II & MultiLoc/TargetLoc & ngLOC & yLoc & Cello \\
\hline & \multicolumn{8}{|c|}{ Probability of Location } \\
\hline $\begin{array}{c}\text { Plasma } \\
\text { membrane }\end{array}$ & - & - & - & $43.5 \%$ & 0.12 & 14.46 & $99.8 \%$ & 4.855 \\
\hline $\begin{array}{l}\text { Endoplasmic } \\
\text { reticulum }\end{array}$ & 0.982 & - & 0.89 & $39.1 \%$ & 0.63 & - & $0.1 \%$ & 0.008 \\
\hline $\begin{array}{l}\text { Extracellular } \\
\text { space }\end{array}$ & - & - & - & $4.3 \%$ & 0.03 & - & $0.1 \%$ & 0.061 \\
\hline Lysosome & - & - & - & - & 0.06 & - & $0.0 \%$ & 0.029 \\
\hline $\begin{array}{c}\text { Golgi } \\
\text { apparatus }\end{array}$ & - & - & - & $4.3 \%$ & 0.14 & - & $0.0 \%$ & - \\
\hline Peroxisome & - & - & - & - & 0.01 & - & $0.0 \%$ & 0.007 \\
\hline Mitochondrion & 0.014 & 0.0097 & 0.00 & $4.3 \%$ & 0.0 & - & $0.0 \%$ & 0.009 \\
\hline Cytoplasm & - & - & - & - & 0.0 & 40.73 & $0.0 \%$ & 0.010 \\
\hline Nucleus & - & - & - & - & 0.0 & 8.909 & $0.0 \%$ & 0.004 \\
\hline
\end{tabular}

The output of each prediction software is an estimated probability or prediction score that correlates with the probability of the predicted localization. The higher the output scores the higher the probability that the protein (GLUT10) is localized in the certain compartment. Empty cells: the prediction tool does not give probability score for this localization.

\subsection{GLUT10 Is Predominantly Present in the Microsomal Fraction}

In a first set of experiments the subcellular localization of GLUT10 was investigated on fractions prepared by differential centrifugation. Immunoblotting of the subcellular fractions derived from human control fibroblasts revealed that the GLUT10 protein was present in the microsomal fraction (ER-derived), whilst virtually absent in the mitochondrial fraction (Figure 1A). The fraction identity was validated by the presence of suitable marker proteins, in particular the ER marker Grp94 was largely associated to the same microsomal fraction, while the mitochondrial and cytoplasmic markers-VDAC1/cyclophilin D and GAPDH, respectively-were absent or only slightly present in the microsomal fraction (Figure 1A). To further support these findings, the subcellular distribution of GLUT10 was also immunodetected in conventionally prepared liver subcellular fractions. Again, the immunoreactive GLUT10 protein was present in the microsomal but not in the mitochondrial fraction prepared from human liver (Figure 1B). 


\section{(A)}
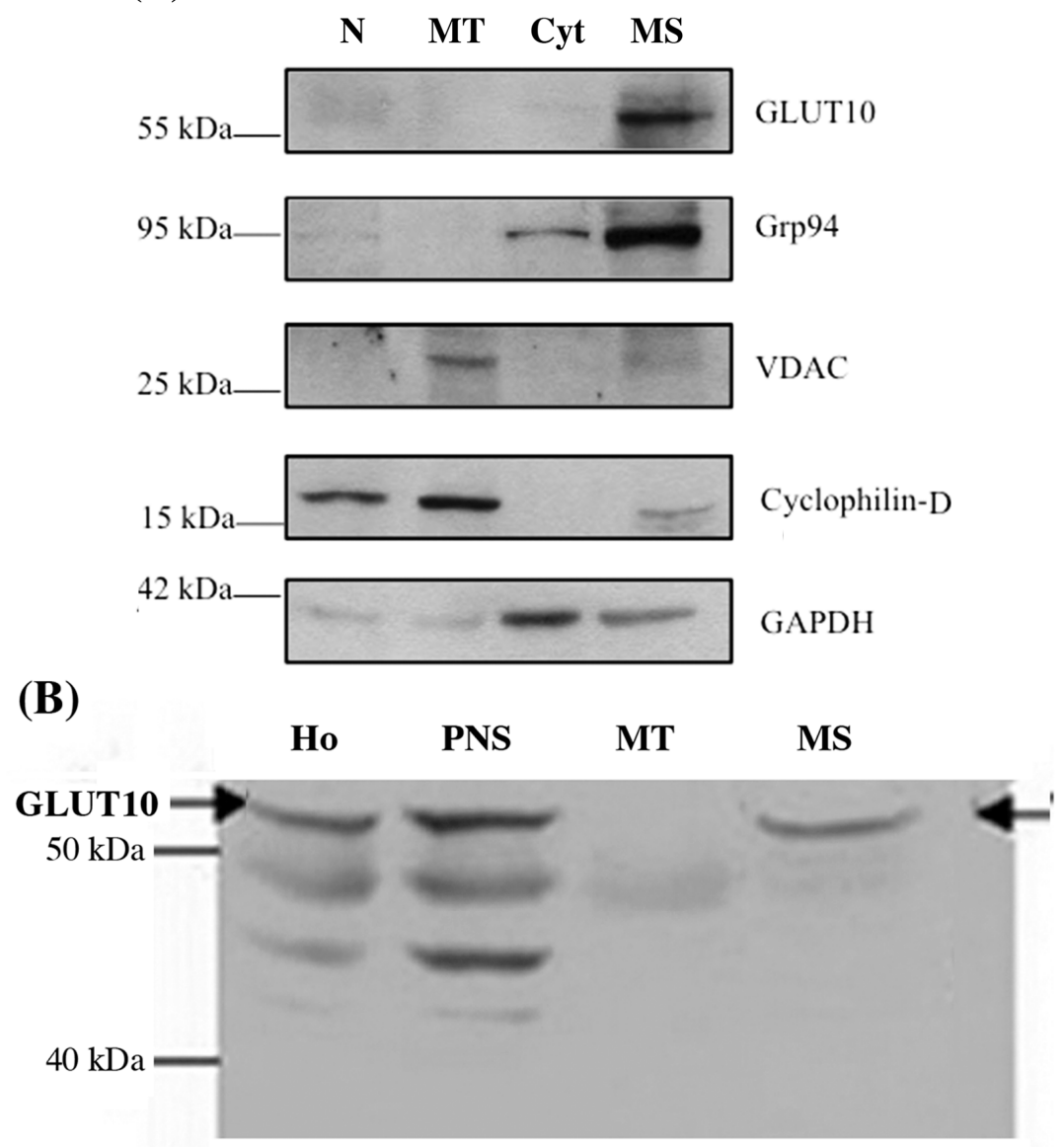

Figure 1. GLUT10 is present in the microsomal fraction of human fibroblasts and liver tissue. Subcellular fractions were prepared from human skin fibroblasts (A) or human liver tissue (B) and analyzed by Western blot after SDS-page separation of proteins, with antibodies to the GLUT10 protein as well as the marker proteins Grp94 for microsomes, VDAC1 and cyclophilin D for mitochondria, and GAPDH for the cytosol, as detailed in the "Experimental" section. Abbreviations: N: Nuclei; MT: mitochondria; Cyt: cytosol; MS: microsomes; Ho: homogenate; PNS: post nuclear supernatant.

\subsection{GLUT10 Immunofluorescence Reveals a Reticular Pattern in Control but Not in ATS Fibroblasts}

Immunofluorescence of human control fibroblasts showed a reticular distribution of the protein and a perinuclear abundance of GLUT10 (Figure 2), as observed in previous studies $[6,18]$. The possible presence of GLUT10 in the mitochondrial network was investigated by localizing mitochondria with the immunoreaction of the cytochrome c protein (Cyt C). The decoration patterns of GLUT10 and of mitochondria were very different (see also enlarged detail in Figure 2). As also shown in Figure 2, GLUT10 could not be detected at all in fibroblasts from the three unrelated ATS patients $[6,9,18]$, while Cyt $C$ decoration was present in a pattern similar to control cells. 


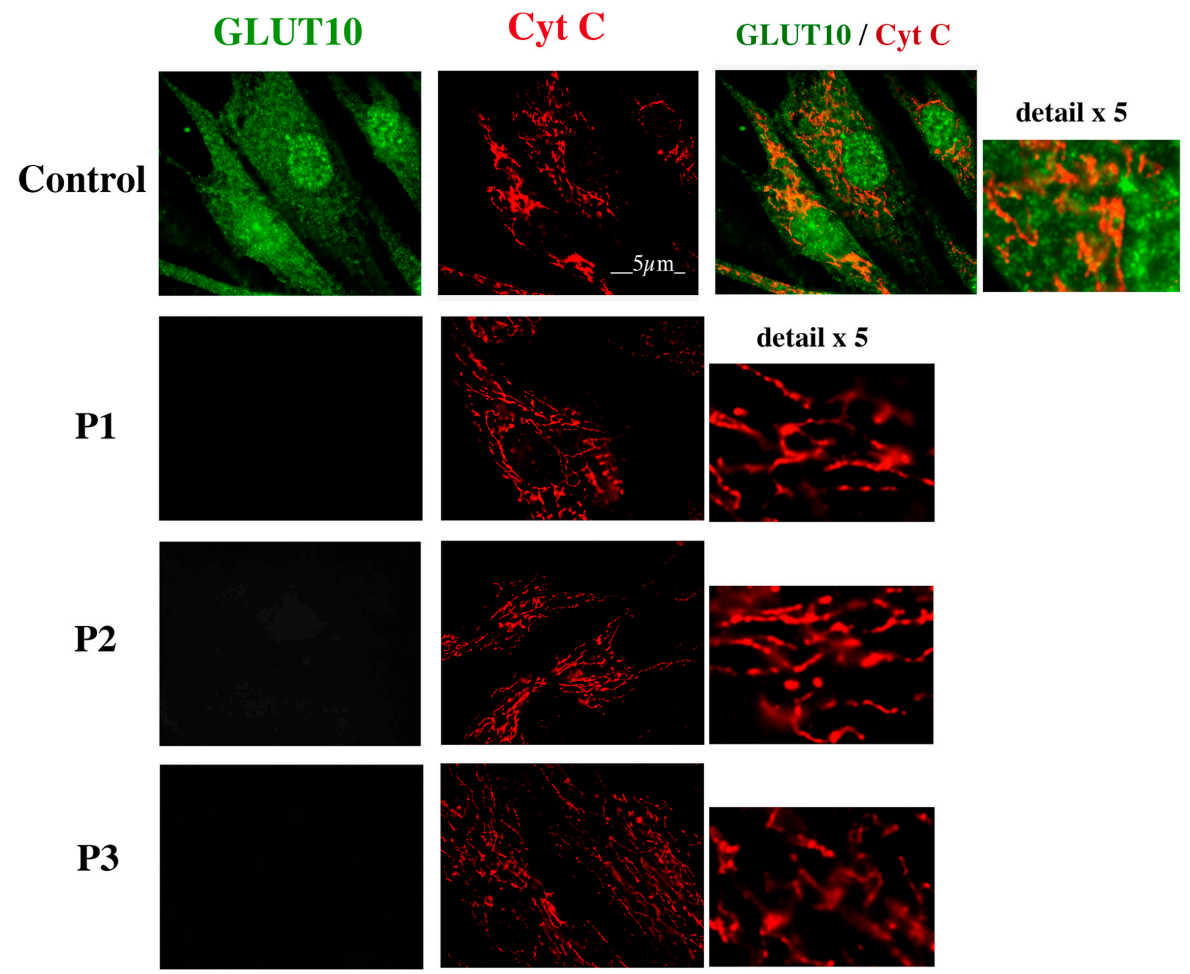

Figure 2. GLUT10 and mitochondrial immunostaining in fibroblasts from human healthy subjects and three arterial tortuosity syndrome (ATS) patients. Fibroblasts were prepared and immunoreacted with the anti-GLUT10 antibody Ab1 and an antibody to Cyt C, and the images were acquired by fluorescent microscopy as detailed in the "Experimental" section. P1, P2 and P3 indicate three unrelated ATS patients as described in the "Experimental" section. Scale bar $=5 \mu \mathrm{m}$.

To further prove the lack of GLUT10 localization to mitochondria, human skin fibroblasts immortalized with human telomerase reverse transcriptase (hTERT) were treated in vivo with a mitochondrial fluorescent probe, and subsequently fixed and immunoreacted for GLUT10. As shown in Figure 3, GLUT10 and mitochondria presented with a very different decoration pattern.

GLUT10

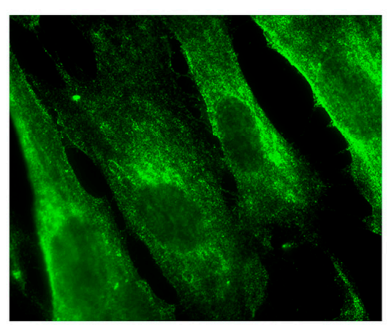

Mito Tracker

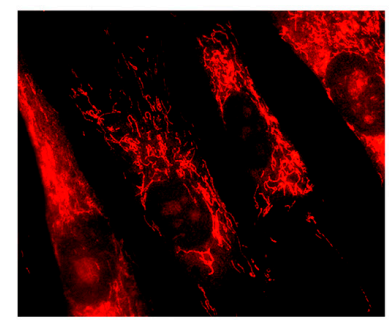

GLUT10/Mito

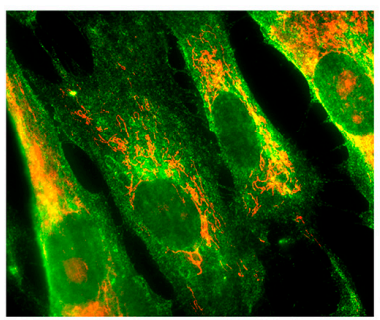

Figure 3. GLUT10 immunostaining and mitochondrial decoration with a fluorescent probe in the human fibroblast cell line BJ-5ta. Human fibroblast immortalized with hTERT (BJ-5ta line) were immunoreacted with the anti-GLUT10 antibody Ab2, and the mitochondrial fluorescent probe Mito Tracker ${ }^{\mathrm{TM}}$ Orange as reported in the "Experimental" section. Images were acquired by fluorescent microscopy as detailed in the "Experimental" section. Scale bar $=5 \mu \mathrm{m}$.

\subsection{GLUT10 Co-Localizes with the ER Marker Protein PDI}

Our previous efforts for the demonstration of GLUT10 co-localization with an ER marker have failed. Although antibodies to several ER markers have been tested, GLUT10 immunoreaction 
somehow quenched the labeling of the ER marker proteins. To overcome this problem, tagged GLUT10 was transiently transfected into fibroblasts of the ATS patient P1. This approach resulted in the decoration of both tagged GLUT10 and the ER marker protein disulfide isomerase (PDI) (Figure 4). An evident co-localization of GLUT10 and PDI was present with an intense perinuclear decoration (see also details in Figure 4).
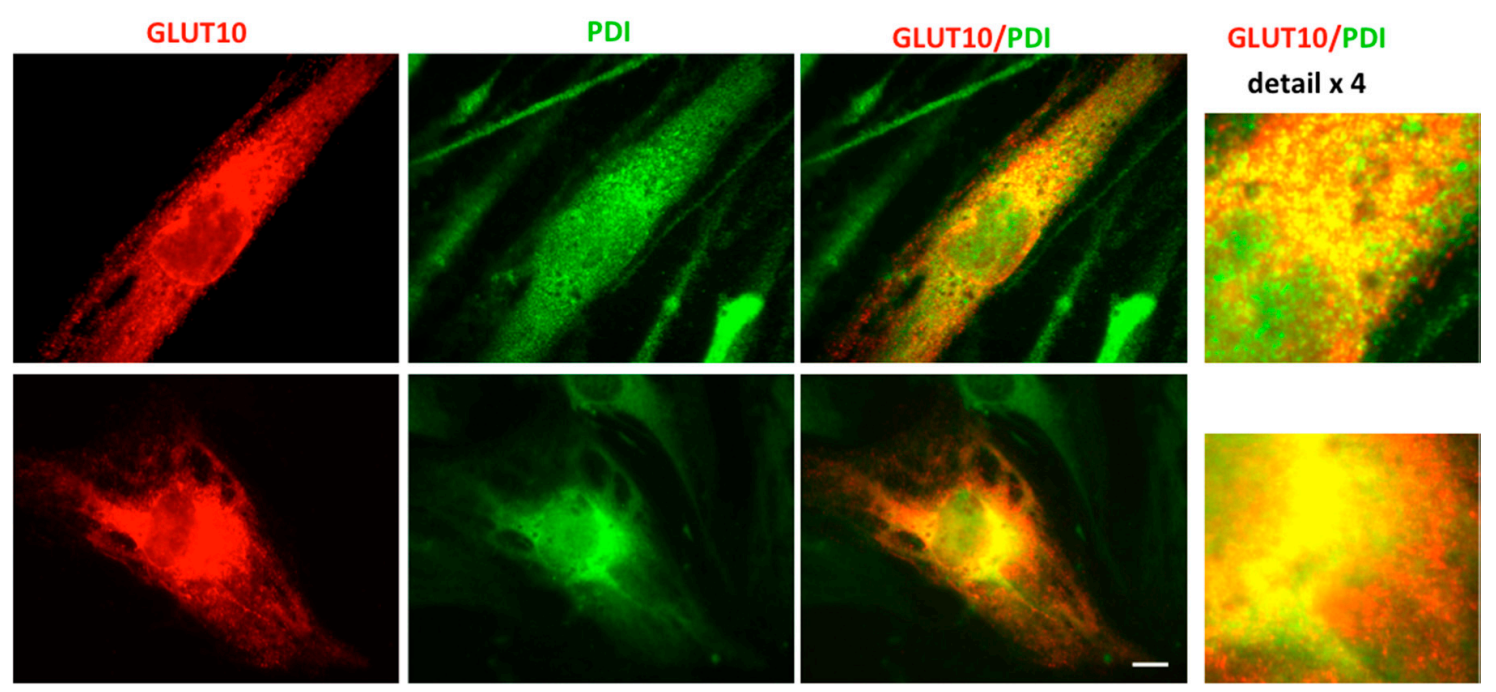

Figure 4. GLUT10 co-localizes with the ER marker protein disulfide isomerase (PDI). Tagged GLUT10 was transiently transfected in fibroblasts of the ATS patient P1 that were immunoreacted with antibodies to the GLUT10 tag and the ER marker PDI as reported in the "Experimental" section. The images were acquired by fluorescent microscopy as detailed in the "Experimental" section. Scale bar $=10 \mu \mathrm{m}$.

\section{Discussion}

Pathogenetic mechanisms underlying connective tissue disorganization have not been clarified in details in ATS, in spite of the unequivocally identified mutations in SLC2A10 gene encoding GLUT10 transporter as the genetic cause of the disease. The elucidation of subcellular localization of GLUT10 is crucial for further clarifying the pathomechanism of ATS. The results reported here demonstrate that GLUT10 localizes to the ER and much likely in other elements of the endomembrane system of human fibroblasts. Several lines of evidence support our conclusion.

First, in silico data for the GLUT10 coding sequence suggest ER localization and appear to exclude a mitochondrial one (Table 1).

Second, immunoblotting of the GLUT10 protein revealed its presence in the microsomal (ER-derived) fractions obtained from human fibroblasts and liver tissue, but not in the mitochondrial fractions (Figure 1). The role of GLUT10 in liver pathophysiology—acting either as a DAA or a glucose transporter-is the object of an ongoing study in our laboratories; in any event, the lack of pathology in ATS liver might be due to the presence of multiple DAA/glucose transporters in the liver ER membrane [19].

Third, the immunoreaction of GLUT10 in human fibroblasts revealed an even distribution along the cytosol, with a more intense perinuclear representation of the reactive protein (Figure 2), which strongly suggests ER localization. On the other hand, the mitochondrial network, revealed with both anti-Cyt $C$ antibodies or a mitochondrial probe, presented with a completely different morphology (Figures 2 and 3). The nuclear decoration in control fibroblasts, but not in the hTERT-fibroblast line, might be unspecific as GLUT10 protein was also absent by Western blotting in the fibroblast nuclear fraction. Nonetheless, we cannot fully exclude the decoration of the nucleoplasmic reticulum, which has been reported in many cell types including fibroblasts [20]. In addition to the cell difference, the immunostaining protocol and the antibody to GLUT10 were different in the case of short-term 
cultured fibroblasts (Figure 2) and hTERT-immortalized fibroblast line (Figure 3). In any event, the immunoreaction protocol applied to human fibroblasts (widely used in previous studies) should unequivocally decorate GLUT10, since it did not reveal any signal in three ATS patients (Figure 2), but again revealed the protein after SLC2A10 re-expression in fibroblasts of ATS patients [5]. The lack of immunodetectable GLUT10 protein in the ATS fibroblasts can be easily explained in P1, as his mutations results in the lack of protein expression. The SLC2A10 gene mutations of P2 can theoretically result in a lower expression of the GLUT10 protein with a single amino acid substitution. P3 patient should theoretically produce a smaller protein, as the exon 3-derived amino acid sequence is absent. The logical explanation for these observations is that the modified proteins or their mRNAs are eliminated by a sort of cell quality control [21].

Fourth, the immunorevelation of tagged GLUT10 expressed in ATS fibroblasts from P1 and of the ER classic marker PDI showed a strict co-localization of GLUT10 and PDI (Figure 4). Again, a perinuclear localization of GLUT10 was evident, and the localization pattern was similar to that reported in rat aortic smooth muscle cells transiently expressing the green fluorescent protein-labeled transporter by another author [13].

The original paper of the field already suggested a perinuclear abundance of GLUT10 in human fibroblasts, deciphered as localization in the NE [6]. However, a subsequent study reported that GLUT10 was present in mitochondria and the Golgi apparatus in smooth muscle cells and insulin-stimulated adipocytes of mice [12].

Our results militate against the mitochondrial localization of GLUT10 [12]. This discrepancy might be due to species differences (human in the present study versus mouse in reference 12), and/or to the presence of mitochondria-associated ER membranes (MAMs) [22] in the mitochondrial fractions. It was observed that GLUT10 knock-out mice do not present an evident ATS pathology [8], which makes the mouse model pretty different. Moreover, mitochondria are equipped with several other AA and DAA transporters [23-26], which questions the importance of GLUT10 as a mitochondrial transporter [27]; consistently, we observed a similar mitochondrial DAA uptake in control and ATS fibroblasts As to the reported localization of GLUT10 to the Golgi [12], it was observed in murine 3T3-L1 cell line only, but not in rat A10 smooth muscle cells, and therefore species/cell-type differences might account for these discrepancies. Although we cannot fully exclude the presence of the transporter also in the Golgi of human fibroblasts, the even distribution of GLUT10 indicates a widespread ER localization being the Golgi only a minor portion of the endomembrane network.

The function of DAA and/or AA that is missing in the ER lumen of fibroblasts from ATS patients is still enigmatic. Besides the plausible antioxidant role, AA serves as a cofactor of $\mathrm{Fe}^{2+}$ /2-oxoglutarate-dependent dioxygenases [28]. This group of the enzymes includes hydroxylases involved in the posttranslational modification of collagen, elastin and other extracellular matrix proteins in the ER [29]. Thus, shortage of AA in the ER luminal compartment can depress the formation of extracellular matrix proteins. Moreover, GLUT10 in the ER-derived NE by allowing the entry of DAA in the nucleoplasma can regulate the activity of various nuclear $\mathrm{Fe}^{2+} / 2$-oxoglutarate-dependent dioxygenases, which catalyze the demethylation of histones and nucleic acids as well as the hydroxylation of certain histones and also participate in DNA repairing processes [15]. Together, such epigenetic and posttranslational events can result in the pathological changes of ATS fibroblasts [15]. In accordance with this assumption, altered gene expression has been observed in a recently published transcriptome analyses performed in ATS fibroblasts [18]. The reported changes affected the expression of numerous genes involved not only in TGF $\beta$ signaling and extracellular matrix formation, but also in specific pathways controlling bioenergetics and oxidative stress response [18]. In summary, the present results and our previous findings [5,18] reinforce the hypothesis that ATS is a vitamin C compartmentalization disease $[13,15]$. Further studies are needed to clarify the molecular details of subcellular mechanisms impaired by AA/DAA depletion in these intracellular compartments. 


\section{Materials and Methods}

\subsection{In Silico Analysis}

The sequence of GLUT10 was retrieved from the Uniprot database (http:/ / www.uniprot.org/). Prediction softwares used: Target P: http:/ / www.cbs.dtu.dk/services/TargetP / [30]; Mitoprot II: http:/ /ihg.gsf.de/ihg/mitoprot.html [31]; Predotar: https://urgi.versailles.inra.fr/predotar/predotar. html [32]; Psort II: http://psort.hgc.jp/form2.html [33]; MultiLoc/TargetLoc: http:/ /abi.inf.unituebingen.de/Services/MultiLoc/ [34]; ngLOC: http:/ /genome.unmc.edu/ngLOC/index.html [35]; YLoc: http:/ / abi.inf.uni-tuebingen.de/Services/YLoc/webloc.cgi [36] and CELLO v2.5: http:/ / cello. life.nctu.edu.tw/ [37]. The reliability of the prediction tools has been double-checked by testing GLUT1-4 proteins and the ER marker protein CYP2E1

\subsection{Fibroblast Culture}

Skin fibroblasts from three ATS patients and unrelated healthy donors were established from skin biopsies as previously reported $[6,18]$. The ATS patients were: patient 1 (P1) homozygous for the c.1334delG microdeletion [6]; patient 2 (P2) compound heterozygous for the c.1309G > A and the c.1330C > T transitions [7]; patient 3 (P3) homozygous for the c.1411+1G > A splicing mutation [9]. Written informed consent was obtained from the patients and healthy individuals for skin biopsy procedure. This study was approved by the medical ethical committee of the University Hospital Spedali Civili of Brescia, Italy, and was performed in accordance with the Declaration of Helsinki Principles. A human skin fibroblast cell line immortalized with hTERT (BJ-5ta) was purchased from LGC Standards (Teddington, Middlesex, UK).

Fibroblasts from healthy subjects and ATS patients were grown in vitro at $37^{\circ} \mathrm{C}$ in a $5 \% \mathrm{CO}_{2}$ atmosphere in Earle's Modified Eagle Medium (MEM) supplemented with 2 mM L-glutamine, $10 \%$ fetal bovine serum, $100 \mu \mathrm{g} / \mathrm{mL}$ penicillin and streptomycin (Life Technologies, Carlsbad, CA, USA). Cells were analyzed at the same in vitro passage number (5th to 7 th). BJ-5ta fibroblasts were grown in a 4:1 mixture of MEM and Medium199 supplemented with $0.01 \mathrm{mg} / \mathrm{mL}$ hygromycin B (Life Technologies, Carlsbad, CA, USA), 10\% fetal bovine serum and 1\% Antibiotic-Antimycotic (Life Technologies). All cultures were grown in humidified incubator at $37{ }^{\circ} \mathrm{C}$ with a $5 \% \mathrm{CO}_{2}$ in air atmosphere.

\subsection{Subcellular Fractionation of Human Fibroblasts}

Subcellular fractions were prepared from human control fibroblasts as reported earlier [38] with minor modifications. Cell homogenates were centrifuged for $10 \mathrm{~min}$ at $1000 \times \mathrm{g}$. The postnuclear supernatants were centrifuged for $20 \mathrm{~min}$ at $18,000 \times g$ to obtain mitochondrial fraction. Microsomes were recovered by ultracentrifugation for $60 \mathrm{~min}$ at $195,000 \times \mathrm{g}$. Pellets were resuspended in $20 \mathrm{mM}$ 3-(N-morpholino)propanesulfonic acid (MOPS) buffer ( $\mathrm{pH} 7.2$ ) and maintained in liquid $\mathrm{N}_{2}$.

\subsection{Preparation of Subcellular Fractions from Human Liver}

Subcellular fractions from human liver were performed as described earlier [39]. The human liver samples were portions of tissue obtained under surgical operation the Semmelweis University. The liver samples were graded by a pathologist on routine histochemistry on a scale of $1-5$, and only liver samples graded 1 (1 being apparently normal and 5 severely diseased) were used.

\subsection{Western Blot Analysis}

Western blots were carried out as described previously [39]; $20 \mu$ g protein was loaded from each fraction. The membranes were incubated with antibodies against GLUT10 (1:1000, Abcam, Cambridge, UK), voltage dependent anion channel 1 (VDAC1) (1:1000; Santa Cruz Biotechnology, Inc., Dallas, TX, 
USA), cyclophilin D (1:2000; MitoSciences, Eugene, OR, USA), Grp94 and glyceraldehyde-3-phosphate dehydrogenase (GAPDH) (1:5000; Santa Cruz Biotechnology, Inc., Dallas, TX, USA).

\subsection{Construction of a Tagged-pG10 Expression Vector}

Ten nanograms of the pG10 expression vector $[5,18]$ were used as PCR template to amplify the full-length coding sequence of $S L C 2 A 10$, from the Kozak consensus sequence to the last amino acid codon. The PCR product was gel-purified and directly inserted into the $\mathrm{pEF} 6 / \mathrm{V} 5-\mathrm{His}-\mathrm{TOPO}{ }^{\mathrm{TM}}$ expression vector according to the manufacturer's instructions (Life Technologies, Carlsbad, CA, USA). Prior to transfection, the pG10-tag plasmid was sequenced to verify the correct in-frame insertion of GLUT10 with the C-terminal V5-His amino acids present on the expression vector. Transient transfection of pG10-tag into skin fibroblasts of the ATS patient P1 was achieved using the TurboFect transfection reagent in accordance with the manufacturer's instructions (Thermo Scientific, Waltham, MA, USA).

\subsection{Immunofluorescence Microscopical Analysis}

To immunoreveal the GLUT10 protein, control and ATS fibroblasts were grown $48 \mathrm{~h}$ and reacted for 2 min with 3\% paraformaldehyde/0.5\% Triton, 20 min with 3\% paraformaldehyde, washed with $100 \mathrm{mM}$ glycine/phosphate buffered saline (PBS), blocked for $30 \mathrm{~min}$ with $5 \%$ bovine serum albumin (BSA) and immunoreacted overnight at $+4{ }^{\circ} \mathrm{C}$ with $20 \mu \mathrm{g} / \mathrm{mL}$ rabbit polyclonal anti-human GLUT10 antibody (Alpha Diagnostic Int. Inc., San Antonio, TX, USA), referred to here as Ab1. After washing in PBS, cells were incubated for $1 \mathrm{~h}$ at room temperature with 1:1000 anti-rabbit secondary antibody conjugated to Alexa Fluor 488. The double staining was performed immunoreacting with $2 \mu \mathrm{g} / \mathrm{mL}$ anti-Cyt $\mathrm{C}$ monoclonal antibody (clone 6H2-B4) for $2 \mathrm{~h}$ and with an anti-mouse secondary antibody conjugated to Alexa Fluor 594. In certain experiments, human BJ-5ta fibroblasts grown on cover slides were incubated with $200 \mathrm{nM}$ Mito Traker ${ }^{\mathrm{TM}}$ Orange (Molecular probes, Thermo Fisher Scientific, Waltham, MA, USA) for $15 \mathrm{~min}$ at $37^{\circ} \mathrm{C}$, washed and fixed with $4 \%$ paraformaldehyde for $15 \mathrm{~min}$, treated with cold $\left(-20^{\circ} \mathrm{C}\right)$ acetone, washed with PBS, blocked for $30 \mathrm{~min}$ with $2 \%$ BSA and immunoreacted overnight at $+4{ }^{\circ} \mathrm{C}$ with rabbit polyclonal anti-human GLUT10 antibody (1:200, Abnova, Walnut, CA, USA), referred to here as Ab2. After washing in PBS, cells were incubated for $1 \mathrm{~h}$ at room temperature with 1:2000 anti-rabbit secondary antibody conjugated to Alexa Fluor 488.

The signals were acquired by a cooled digital camera, DS Qi1, (Nikon, Japan) mounted on a Nikon Eclipse Ti inverted fluorescence microscope. The experiments were repeated three times.

The co-localization of GLUT10 with the protein disulfide isomerase (PDI) was analyzed in the ATS fibroblasts from P1 by transient transfection of tagged GLUT10. Fibroblasts grown for $48 \mathrm{~h}$ were fixed in cold methanol and immunoreacted for $2 \mathrm{~h}$ with 1:100 rabbit polyclonal anti-PDI antibody (Novus Biologicals, Littleton, CO, USA), which labels ER, and $1 \mu \mathrm{g} / \mathrm{mL}$ anti-V5 monoclonal antibody (Sigma Chemicals, St. Louis, MO, USA) to label tagged GLUT10. Cells were incubated for $1 \mathrm{~h}$ with 1:1000 anti-rabbit and anti-mouse secondary Abs conjugated to Alexa Fluor ${ }^{\circledR} 488$ and 594, respectively. Immunofluorescence signals were acquired by a CCD camera (SensiCam-PCO Computer Optics $\mathrm{GmbH}$, Kelheim, Germany) mounted on Zeiss fluorescence Axiovert microscope (Zeiss, Oberkochen, Germany). The experiments were repeated three times.

Acknowledgments: This work was supported by the Hungarian Scientific Research Fund (OTKA), Grants 100293, 111031, 112696, 105246, 124442, by a Hungarian-Flemish Mobility Grant of the Hungarian Academy of Sciences (NKM-52/2016), by the Telethon Grant n.GGP13167 to Marina Colombi, by Ghent University (Methusalem grant BOF08/01M01108) and by the Fund for Scientific Research-Flanders (Research Project G057413N). Éva Margittai was supported by the MedInProt Protein Science Research Synergy Program of the Hungarian Academy of Sciences.

Author Contributions: Paola Marcolongo and Alessandra Gamberucci performed the experiments in hTERT fibroblasts, contributed to immunohistochemistry, and drafted the manuscript; Csilla E. Németh executed the subcellular fractionation experiments on fibroblasts and analyzed the localization of GLUT10 by gel electrophoresis and immunostaining; András Szarka performed the in silico analyses for the prediction of GLUT10 localization; 
Marina Colombi and Marco Ritelli performed the clinical and molecular diagnosis of the ATS patients, respectively; Marco Ritelli, Nicola Chiarelli, and Giulia Carini prepared the tagged GLUT10 expression vector and performed transfection experiments; Nicoletta Zoppi prepared and characterized human fibroblasts from control individuals and ATS patients and performed immunofluorescence analysis of GLUT10 and its co-localization experiments with PDI; Tamás Hegedús contributed to materials and data analyses; Paul J. Coucke, Andy Willaert and Bert L. Callewaert contributed to reagents and materials; Éva Margittai did the subcellular fractionation of human liver tissue and the analyses of the samples; Rosella Fulceri and Angiolo Benedetti contributed to reagents and materials for immunofluorescence measurements and analysed the results; Gábor Bánhegyi conceived and designed the experiments and contributed to the majority of general lab equipment and reagents. All authors participated in the design of the study and in the writing of the manuscript.

Conflicts of Interest: The authors declare no conflict of interest.

\section{Abbreviations}

$\begin{array}{ll}\text { AA } & \text { Ascorbic acid } \\ \text { ATS } & \text { Arterial tortuosity syndrome } \\ \text { BSA } & \text { Bovine serum albumin } \\ \text { Cyt C } & \text { Cytochrome C } \\ \text { DAA } & \text { Dehydroascorbic acid } \\ \text { ER } & \text { Endoplasmic reticulum } \\ \text { GAPDH } & \text { Glyceraldehyde-3-phosphate dehydrogenase } \\ \text { GLUT } & \text { Glucose transporter } \\ \text { hTERT } & \text { Human telomerase reverse transcriptase } \\ \text { KRR } & \text { Lys-Arg-Arg } \\ \text { MOPS } & \text { 3-(N-morpholino)propanesulfonic acid } \\ \text { NE } & \text { Nuclear envelope } \\ \text { PBS } & \text { Phosphate buffered saline } \\ \text { PDI } & \text { Protein disulfide isomerase } \\ \text { TGF } \beta & \text { Transforming growth factor beta } \\ \text { VDAC } & \text { Voltage dependent anion channel }\end{array}$

\section{References}

1. Deng, D.; Yan, N. GLUT, SGLT, and SWEET: Structural and mechanistic investigations of the glucose transporters. Protein Sci. 2016, 25, 546-558. [CrossRef] [PubMed]

2. Dawson, P.A.; Mychaleckyj, J.C.; Fossey, S.C.; Mihic, S.J.; Craddock, A.L.; Bowden, D.W. Sequence and functional analysis of GLUT10: A glucose transporter in the Type 2 diabetes-linked region of chromosome 20q12-13.1. Mol. Genet. Metab. 2001, 74, 186-199. [CrossRef] [PubMed]

3. Nagai, K.; Inoue, T.; Konishi, H. Increased gene expression of glucose transporters in the mouse brain after treatment with fluoxetine and pergolide. Drug Res. 2014, 64, 389-391. [CrossRef] [PubMed]

4. Pyla, R.; Poulose, N.; Jun, J.Y.; Segar, L. Expression of conventional and novel glucose transporters, GLUT1, $-9,-10$, and -12 , in vascular smooth muscle cells. Am. J. Physiol. Cell Physiol. 2013, 304, 574-589. [CrossRef] [PubMed]

5. Németh, C.E.; Marcolongo, P.; Gamberucci, A.; Fulceri, R.; Benedetti, A.; Zoppi, N.; Ritelli, M.; Chiarelli, N.; Colombi, M.; Willaert, A.; et al. Glucose transporter type 10-lacking in arterial tortuosity syndrome-facilitates dehydroascorbic acid transport. FEBS Lett. 2016, 590, 1630-1640. [CrossRef] [PubMed]

6. Coucke, P.J.; Willaert, A.; Wessels, M.W.; Callewaert, B.; Zoppi, N.; de Backer, J.; Fox, J.E.; Mancini, G.M.; Kambouris, M.; Gardella, R.; et al. Mutations in the facilitative glucose transporter GLUT10 alter angiogenesis and cause arterial tortuosity syndrome. Nat. Genet. 2006, 38, 452-457. [CrossRef] [PubMed]

7. Drera, B.; Guala, A.; Zoppi, N.; Gardella, R.; Franceschini, P.; Barlati, S.; Colombi, M. Two novel SLC2A10/GLUT10 mutations in a patient with arterial tortuosity syndrome. Am. J. Med. Genet. 2007, 143, 216-218. [CrossRef] [PubMed]

8. Callewaert, B.L.; Loeys, B.L.; Casteleyn, C.; Willaert, A.; Dewint, P.; de Backer, J.; Sedlmeier, R.; Simoens, P.; de Paepe, A.M.; Coucke, P.J. Absence of arterial phenotype in mice with homozygous slc2A10 missense substitutions. Genesis 2008, 46, 385-389. [CrossRef] [PubMed]

9. Castori, M.; Ritelli, M.; Zoppi, N.; Chiarelli, N.; Molisso, L.; Zaccagna, F.; Grammatico, P.; Colombi, M. Adult presentation of arterial tortuosity syndrome in a 51-year-old woman with the novel homozygous c.1411+1G > A mutation in the SLC2A10 gene. Am. J. Med. Genet. 2012, 158, 1164-1169. [CrossRef] [PubMed] 
10. Callewaert, B.; de Paepe, A.; Coucke, P. Arterial Tortuosity Syndrome. In Gene Reviews ${ }^{\circledR}$; Internet; Pagon, R.A., Adam, M.P., Ardinger, H.H., Wallace, S.E., Amemiya, A., Bean, L.J.H., Bird, T.D., Dolan, C.R., Fong, C.T., Smith, R.J.H., et al., Eds.; University of Washington: Seattle, WA, USA, 2014; pp. 1993-2015. Available online: http:/ / www.ncbi.nlm.nih.gov/books/NBK253404/ (accessed on 22 August 2017).

11. Ritelli, M.; Chiarelli, N.; Dordoni, C.; Reffo, E.; Venturini, M.; Quinzani, S.; Monica, M.D.; Scarano, G.; Santoro, G.; Russo, M.G.; et al. Arterial Tortuosity Syndrome: Homozygosity for two novel and one recurrent SLC2A10 missense mutations in three families with severe cardiopulmonary complications in infancy and a literature review. BMC Med. Genet. 2014, 15, 122-131. [CrossRef] [PubMed]

12. Lee, Y.C.; Huang, H.Y.; Chang, C.J.; Cheng, C.H.; Chen, Y.T. Mitochondrial GLUT10 facilitates dehydroascorbic acid import and protects cells against oxidative stress: Mechanistic insight into arterial tortuosity syndrome. Hum. Mol. Genet. 2010, 19, 3721-3733. [CrossRef] [PubMed]

13. Segade, F. Glucose transporter 10 and arterial tortuosity syndrome: The vitamin C connection. FEBS Lett. 2010, 584, 2990-2994. [CrossRef] [PubMed]

14. Bánhegyi, G.; Marcolongo, P.; Puskas, F.; Fulceri, R.; Mandl, J.; Benedetti, A. Dehydroascorbate and ascorbate transport in rat liver microsomal vesicles. J. Biol. Chem. 1998, 273, 2758-2762. [CrossRef] [PubMed]

15. Bánhegyi, G.; Benedetti, A.; Margittai, E.; Marcolongo, P.; Fulceri, R.; Németh, C.E.; Szarka, A. Subcellular compartmentation of ascorbate and its variation in disease states. Biochim. Biophys. Acta 2014, 1843, 1909-1916. [CrossRef] [PubMed]

16. Joost, H.G.; Thorens, B. The extended GLUT-family of sugar/polyol transport facilitators: Nomenclature, sequence characteristics, and potential function of its novel members (review). Mol. Membr. Biol. 2001, 18, 247-256. [CrossRef] [PubMed]

17. Girard, C.; Tinel, N.; Terrenoire, C.; Romey, G.; Lazdunski, M.; Borsotto, M. p11, an annexin II subunit, an auxiliary protein associated with the background $\mathrm{K}^{+}$channel, TASK-1. EMBO J. 2002, 21, 4439-4448. [CrossRef] [PubMed]

18. Zoppi, N.; Chiarelli, N.; Cinquina, V.; Ritelli, M.; Colombi, M. GLUT10 deficiency leads to oxidative stress and non-canonical $\alpha \mathrm{v} \beta 3$ integrin-mediated TGF $\beta$ signalling associated with extracellular matrix disarray in arterial tortuosity syndrome skin fibroblasts. Hum. Mol. Genet. 2015, 24, 6769-6787. [CrossRef] [PubMed]

19. Bánhegyi, G.; Marcolongo, P.; Burchell, A.; Benedetti, A. Heterogeneity of glucose transport in rat liver microsomal vesicles. Arch. Biochem. Biophys. 1998, 359, 133-138. [CrossRef] [PubMed]

20. Malhas, A.; Goulbourne, C.; Vaux, D.J. The nucleoplasmic reticulum: Form and function. Trends Cell. Biol. 2011, 21, 362-373. [CrossRef] [PubMed]

21. McCaffrey, K.; Braakman, I. Protein quality control at the endoplasmic reticulum. Essays Biochem. 2016, 60, 227-235. [CrossRef] [PubMed]

22. Hayashi, T.; Rizzuto, R.; Hajnoczky, G.; Su, T.P. MAM: More than just a housekeeper. Trends Cell Biol. 2009, 19, 81-88. [CrossRef] [PubMed]

23. Szarka, A.; Horemans, N.; Bánhegyi, G.; Asard, H. Facilitated glucose and dehydroascorbate transport in plant mitochondria. Arch Biochem. Biophys. 2004, 428, 73-80. [CrossRef] [PubMed]

24. KC, S.; Cárcamo, J.M.; Golde, D.W. Vitamin C enters mitochondria via facilitative glucose transporter 1 (Glut1) and confers mitochondrial protection against oxidative injury. FASEB J. 2005, 19, 1657-1667. [CrossRef] [PubMed]

25. Azzolini, C.; Fiorani, M.; Cerioni, L.; Guidarelli, A.; Cantoni, O. Sodium-dependent transport of ascorbic acid in U937 cell mitochondria. IUBMB Life 2013, 65, 149-153. [CrossRef] [PubMed]

26. Muñoz-Montesino, C.; Roa, F.J.; Peña, E.; González, M.; Sotomayor, K.; Inostrosa, E.; Muñoz, C.; González, I.; Maldonado, M.; Soliz, C.; et al. Mitochondrial ascorbic acid transport is mediated by a low-affinity form of the sodium-coupled ascorbic acid transporter-2. Free Radic. Biol. Med. 2014, 70, 241-254. [CrossRef] [PubMed]

27. Szarka, A.; Balogh, T. In silico aided thoughts on mitochondrial vitamin C transport. J. Theor. Biol. 2015, 365, 181-189. [CrossRef] [PubMed]

28. Kuiper, C.; Vissers, M.C. Ascorbate as a co-factor for Fe- and 2-oxoglutarate dependent dioxygenases: Physiological activity in tumor growth and progression. Front. Oncol. 2014, 4, 359. [CrossRef] [PubMed]

29. Myllyharju, J. Prolyl 4-hydroxylases, key enzymes in the synthesis of collagens and regulation of the response to hypoxia, and their roles as treatment targets. Ann. Med. 2008, 40, 402-417. [CrossRef] [PubMed] 
30. Emanuelsson, O.; Nielsen, H.; Brunak, S.; von Heijne, G. Predicting subcellular localization of proteins based on their N-terminal amino acid sequence. J. Mol. Biol. 2000, 300, 1005-1016. [CrossRef] [PubMed]

31. Claros, M.G.; Vincens, P. Computational method to predict mitochondrially imported proteins and their targeting sequences. Eur. J. Biochem. 1996, 241, 779-786. [CrossRef] [PubMed]

32. Small, I.; Peeters, N.; Legeai, F.; Lurin, C. Predotar: A tool for rapidly screening proteomes for N-terminal targeting sequences. Proteomics 2004, 4, 1581-1590. [CrossRef] [PubMed]

33. Nakai, K.; Horton, P. PSORT: A program for detecting sorting signals in proteins and predicting their subcellular localization. Trends Biochem. Sci. 1999, 24, 34-36. [CrossRef]

34. Höglund, A.; Dönnes, P.; Blum, T.; Adolph, H.W.; Kohlbacher, O. MultiLoc: Prediction of protein subcellular localization using $\mathrm{N}$-terminal targeting sequences, sequence motifs and amino acid composition. Bioinformatics 2006, 22, 1158-1165. [CrossRef] [PubMed]

35. King, B.R.; Vural, S.; Pandey, S.; Barteau, A.; Guda, C. ngLOC: Software and web server for predicting protein subcellular localization in prokaryotes and eukaryotes. BMC Research Notes 2012, 5, 351. [CrossRef] [PubMed]

36. Briesemeister, S.; Rahnenführer, J.; Kohlbacher, O. YLoc-an interpretable web server for predicting subcellular localization. Nucleic Acids Res. 2010, 38, 497-502. [CrossRef] [PubMed]

37. Yu, C.S.; Chen, Y.C.; Lu, C.H.; Hwang, J.K. Prediction of protein subcellular localization. Proteins 2006, 64, 643-651. [CrossRef] [PubMed]

38. Leuzzi, R.; Fulceri, R.; Marcolongo, P.; Bánhegyi, G.; Zammarchi, E.; Stafford, K.; Burchell, A.; Benedetti, A. Glucose 6-phosphate transport in fibroblast microsomes from glycogen storage disease type $1 \mathrm{~b}$ patients: Evidence for multiple glucose 6-phosphate transport systems. Biochem. J. 2001, 357, 557-562. [CrossRef] [PubMed]

39. Margittai, É.; Bánhegyi, G. Isocitrate dehydrogenase: A NADPH-generating enzyme in the lumen of the endoplasmic reticulum. Arch. Biochem. Biophys. 2008, 471, 184-190. [CrossRef] [PubMed]

(C) 2017 by the authors. Licensee MDPI, Basel, Switzerland. This article is an open access article distributed under the terms and conditions of the Creative Commons Attribution (CC BY) license (http:/ / creativecommons.org/licenses/by/4.0/). 